\title{
$60 \mathrm{~Hz}$ frequency effect on gait in Parkinson's disease with subthalamic nucleus deep brain stimulation
}

\author{
Fenna T. Phibbs, M.D., MPH ${ }^{1}$, Patrick G. Arbogast, PhD $^{2}$, and Thomas L. Davis, M.D. ${ }^{1}$ \\ ${ }^{1}$ Vanderbilt department of Neurology, Movement Disorders, Nashville TN \\ ${ }^{2}$ Vanderbilt department of Biostatistics, Nashville TN
}

\begin{abstract}
Background-Gait dysfunction is common in advancing Parkinson's disease and has a disappointing response to dopamine replacement and subthalamic nucleus deep brain stimulation programming parameters. Low frequency stimulation, less than $130 \mathrm{Hertz}$ in combination with increased voltage has been shown to decrease freezing episodes and number of steps with little impact on overall performance measured by the Unified Parkinson's Disease Rating Scale. This was in the setting of delivering the same total energy, which required both a change in voltage, and frequency. We wanted to determine if the benefit came from low frequency alone.
\end{abstract}

Methods-We enrolled 20 Parkinson's patients who were at least 3 months post bilateral subthalamic deep brain stimulation and reported gait changes. Subjects held their Parkinson's medications overnight and following a baseline evaluation were randomly assigned to both 60 and 130 Hertz stimulation in a blinded fashion with all other parameters held constant. Each subject was set at each frequency twice during the study, with a 60-minute stimulation interval prior to each gait evaluation.

\begin{abstract}
Results-There was no significant difference between the two frequencies, with the primary outcome measure of stride length. Two of the 20 patients reported a significant subjective improvement in their gait with no statistical difference in their outcomes. There was also less tremor control at 60 Hertz.
\end{abstract}

Conclusion-We were unable to demonstrate improved gait with lower frequency stimulation as suggested by prior studies. This may have been due to the decreased energy delivered from the lower frequency and unchanged voltage.

\footnotetext{
Corresponding Author: Fenna T Phibbs MD MPH, A-0118 MCN, Vanderbilt Medical Center, Nashville, TN, 37232-2551, 615-936-2025-phone, 615-936-1229-fax, Fenna.phibbs@vanderbilt.edu.

Authorship statement

Dr. Phibbs assisted with study conception and design, data collection, data analysis and preparation of the manuscript.

Dr. Arbogast assisted with study design, data analysis and review of the manuscript

Dr. Davis assisted with study conception and design, data analysis and critical review of the manuscript.

Conflict of interest:

Fenna T. Phibbs has received speaking honoraria from Teva pharmaceuticals and has done consulting work for Boston Scientific and Medtronic.

Patrick G. Arbogast passed away in the summer of 2012

Thomas L. Davis has done consulting work for Medtronic.
} 


\section{Keywords}

STN; Parkinson's disease; Gait; Low frequency; 60 Hertz; freezing of gait

\section{Introduction}

As Parkinson's disease (PD) progresses gait dysfunction with falls results in significant disability and loss of independence (1-7). With advancing disease, there is a decrease in stride length, the distance between two consecutive heal strikes of the same foot, and an increase in the number of steps and freezing episodes (8). Since gait dysfunction often does not respond well to medication or deep brain stimulation (DBS), it is thought to be caused by nondopaminergic degeneration (9) or by changes in other neuronal systems that are beyond the reach of common DBS targets or traditionally used stimulation parameters that are directed at medication responsive symptoms. So, with different programming parameters gait dysfunction may improve.

Xie et al recently reported 2 patients who had improvement in freezing of gait (FOG) during their initial DBS programming of bilateral STN implants with a change in frequency from 130 to $60 \mathrm{~Hz}$. There was no worsening of their other Parkinsonian symptoms (10). Other small studies have suggested that gait improves at frequencies between $60-80 \mathrm{~Hz}$, with less FOG, improved stride length, and improved time on the stand-walk-sit test (SWS)(11). This effect may be transient (12). These studies were carried out using a constant Total Electrical Energy Delivered (TEED) that was calculated by the following formula:

$$
\text { TEED }=\text { voltage } 2 \times \text { frequency } \times \text { pulse width/impedance. }{ }_{(13)}
$$

Since the exact mechanism of DBS is unknown, the changes with low frequency stimulation on gait could reflect the increased voltage that was necessary to keep TEED constant. Increased voltage will lead to a larger volume of tissue activated (VTA) and therefore may have an effect on other neuronal systems potentially influencing gait (14). The current commercially available DBS product is not able to precisely measure impedance, due to systematic limitations. This affects the calculation of the TEED, since it is assumes that impedance is constant.

In this study we evaluated the effect of both low $(60 \mathrm{~Hz})$ and high $(130 \mathrm{~Hz})$ frequency stimulation of the STN in PD patients with gait difficulty, to determine if $60 \mathrm{~Hz}$ stimulation will improve gait without worsening of motor scores on the Unified Parkinson's Disease Rating scale (UPDRS).

\section{Methods}

20 patients who reported or were witnessed to have gait changes after STN DBS were referred from the Vanderbilt movement disorders clinic at least three months prior to study enrollment. They gave their consent to participate. The Vanderbilt IRB approved the aims and procedure of the study, registered on Clinicaltrials.gov (NCT00993291Patients were excluded if they were unable to walk independently after holding their Parkinson's 
medications for 12 hours, had a PD medication change in the previous month, had a Mini Mental Status Examination (MMSE) of less than 24 (given that some patients were as far out as 10 years from their DBS surgery), or were otherwise cognitively impaired, or unable to give informed consent.

Patients were admitted to the Clinical Research Center at Vanderbilt Hospital, where they maintained their usual PD medications until 8pm, after which they were held. Starting at approximately 8 am patients underwent a baseline evaluation at their current DBS settings, which included:

- Unified Parkinson's Disease Rating scale, parts II, III and IV (part III was recorded)

- Stand-Walk-Sit test (SWS). Patients were seated in a chair 18 inches from the ground, stood up and walked 7 meters turned around and sat back down. The best time of two trials was used.

- GAITRite ${ }^{\circledR}$ gait evaluation, walked over a 14 foot length carpet, which was placed in the path of the path of the SWS test, allowing for the GAITRite ${ }^{\circledR}$ analysis to occur at the same time. The recording from fastest SWS test was used for data analysis.

After the baseline evaluation subjects were randomized to a frequency series that included both 60 and $130 \mathrm{HZ}$, they were set at each frequency twice during the study session. The frequency series was determined by random number generation using STATA, with predetermined frequency sequences numbered $1-7$. The patient and the video reviewer were blinded to the frequency sequence. Subjects were set at each frequency for one hour prior to evaluation. This time was chosen to replicate the time used by Moreau et al. and to minimize the medication withdrawal effect, and maximize patient comfort. There was also no off medication/off DBS comparison due to the above and the clinical question only involved the change from 130 to $60 \mathrm{~Hz}$, and given the length of the study fluctuating medication effects would confound the results. All other stimulation parameters including voltage and pulse width were unchanged for the duration of the study. All evaluations were completed in one half day session.

At each frequency subjects underwent the following:

- Unified Parkinson's Disease Rating scale, part III only, recorded

- $\quad$ Stand-Walk-Sit test (SWS). The best time of two trials was used

- GAITRite ${ }^{\circledR}$ gait evaluation, the recording from best SWS test was used

The GAITRite ${ }^{\circledR}$ portable gait analysis system has been used to study gait in PD (15). The GAITRite ${ }^{\circledR}$ is a 4.6 meter long 0.89 meter wide electronic walkway that contains pressure sensors organized horizontal grid which when activated allows for data collection on both spatial and temporal aspects of gait. These parameters include stride length, cadence, velocity, single and double limb support time. The recorded UPDRS part III were blindly rated by author TD. 
The primary outcome measure was the change in stride length. Secondary outcomes included the time on the SWS test, other gait parameters collected on the GAITRite ${ }^{\circledR}$ including velocity, cadence, single and double limb support time, and the ratio of the single and double limb support time.

Given the small sample size, the primary analysis is descriptive. For each subject the two 60 $\mathrm{Hz}$ and two $130 \mathrm{~Hz}$ tests were collapsed to two means. Independent measurements for the left and right were combined into a single mean. Baseline continuous data were summarized as medians. Secondary analyses consisted of comparing pair-wise differences between the $60 \mathrm{~Hz}$ and $130 \mathrm{~Hz}$ summarized measures as medians with standard deviations. Secondary outcomes were also summarized as medians.

\section{Results}

1 patient dropped out due to a severe freezing episode and felt that they could not continue. There were 4 women and 16 men. All patients reported multiple changes in their gait, their primary gait complaint was balance (7), freezing (7) and festination (6).

The primary outcome measure of stride length (change from baseline gait assessment) did not show a significant difference between $60 \mathrm{~Hz}$ and $130 \mathrm{~Hz}$. The median stride length change at $60 \mathrm{~Hz}$ stimulation was $1.19 \mathrm{~cm}$ range $(-18.55 \mathrm{~cm}-37.47 \mathrm{~cm})$ and at $130 \mathrm{~Hz}$, the median change in stride length was $2.86 \mathrm{~cm}$ range $(-11.33 \mathrm{~cm}-31.93 \mathrm{~cm})$. There was also no significant difference in the analysis based on number of freezes, primary gait complaint, time from DBS surgery, or the frequency sequence. There was also no worsening of motor symptoms on the UPDRS III over the course of the half-day session as may be suspected with a prolonged period off medications. None of the secondary measures showed a significant difference between 60 and $130 \mathrm{~Hz}$ stimulation. There was a trend of decreased double limb support time, which is measured as the percent of time spent on 2 feet during an average gate cycle at $60 \mathrm{~Hz}$ stimulation, with a change of $-0.22 \%$ of the gait cycle range $(-37.65 \%-28.78 \%)$, and for $130 \mathrm{~Hz}$ a change of $10.18 \%$ of the gait cycle range $(-7.80 \%-$ $18.25 \%)$. Of the 14 subjects who had complete data sets for the UPDRS III, there was no significant difference between the frequencies(one subject dropped out and 5 others had one missing item on part III during the 5 evaluations). There was a statistically significant difference with the tremor rating (items 20-21 of the UPDRS III) showing $130 \mathrm{~Hz}$ had better tremor control $(\mathrm{p}=0.0012)$.

Seven of the 20 subjects requested to leave with a different frequency from their baseline. Two of the seven reported a subjective dramatic improvement in their gait. They were both using walkers at the entrance of the study reported that after changing to $60 \mathrm{~Hz}$ stimulation that they no longer required the use of their walker 6 weeks after the study. They reported feeling more stable while walking. At baseline one of the two "responders" had the highest UPDRS scores for "On" and "Off" prior to surgery and also had the highest study baseline UPDRS. Interestingly there was no significant difference in the study outcomes including stride length, velocity, or double for these two patients. 
The only subject to drop out did so after being set at $130 \mathrm{~Hz}$ for an hour, then $60 \mathrm{~Hz}$ for 90 minutes (60 minutes of the second frequency setting and 30 minutes into the third setting). The subject had a severe freezing episode and was feeling poorly from being off medications and elected to drop out. Interestingly there was a increased stride length and increased velocity at $60 \mathrm{~Hz}$ compared to $130 \mathrm{~Hz}$. Up to $5 \mathrm{~cm}$ in the second of the two walks.

\section{Discussion}

We were unable to show that a change to $60 \mathrm{~Hz}$ stimulation alone can improve gait by decreasing the number of steps and freezing episodes. There may be several reasons for this.

The study by Ricchi et al also adjusted the voltage to account for the lower TEED with a change in frequency to $80 \mathrm{~Hz}$. They noted a benefit to the acute change in frequency (3 hours post-change), but this was not sustained at follow up visits starting at 1 month follow up. This was also done in the medication on state with no comment on where patients were in their dosing cycle (12). Xie et al describe two cases of patients who had dopamine responsive FOG prior to DBS implantation who during their initial programming had worsening of FOG with $130 \mathrm{~Hz}$ which immediately improved when only the frequency was changed to $60 \mathrm{~Hz}$, this was sustained at a 10 month follow up visit (10).

The study by Moreau and report by Xie showed an increase in the number of steps and FOG episodes with high voltage and $130 \mathrm{~Hz}$ stimulation which improved when only the frequency decreased to $60 \mathrm{~Hz}$. Moreau et al also showed that with the usual voltage with minor adjustments for equivalent TEED and $60 \mathrm{~Hz}$ stimulation there was in intermediate improvement in both FOG episodes and the number of steps when compared to high voltage and high frequency stimulation and high voltage low frequency stimulation. One would assume that you are affecting a similar volume of tissue in these two situations and therefore the neuroelements are adversely affected by high frequency stimulation and aided by low frequency as is seen with stimulation of the PPN((1)). Though the PPN is over $5 \mathrm{~mm}$ away from the STN, there are pathways the pass by the STN that may be modulated.

We may mistakenly assume that the gait changes that develop slowly over time after STN DBS implantation are due to disease progression. Xie reported the acute change with the initial DBS settings, but we may induce a slower onset of gait changes with the subsequent DBS programming changes, which most commonly are increases in voltage In our patient population there was no difference in the stride length or number of steps when adjusted for the time from DBS implantation with $60 \mathrm{~Hz}$ stimulation.

Lead location as well as the location of the active contact will affect what tissue is modulated. We were unable to obtain a post-operative MRI on our patients, at the time of the study, so we are unable to determine the exact lead location; this is a limitation of our study. Though it is currently not known where these tracts may be located

Another limitation of our study was the Hawthorne effect. We found that most of our patients did not have replication of their primary or other gait complaints during the study. FOG is known to be very hard to replicate in a clinical setting, but we also did not see a difference in the number of steps or stride length with low frequency. 
We assumed that the gait changes seen in Parkinson's disease are homogenous. The variability across our outcome variables shows this is not the case. For example, on average subjects took less than 20 seconds to complete the stand-walk-sit test (SWS), but one patient, took up to three minutes due to significant freezing of gait. Many of the subject's primary gait complaint did not match what the blinded reviewer felt was the primary problem, which could alter the outcome of the gait change response to low frequency stimulation.

Given the patient adjustable IPG's currently available it is reasonable to try low frequency stimulation on STN implanted PD patients with the complaint of gait changes and freezing of gait, with the best result coming from the highest tolerated voltage and $60 \mathrm{~Hz}$.

\section{Acknowledgments}

This study was supported in part by NIH grant: 1UL 1RR024975 NCRR. This work was partially supported by grant UL1 TR000445 from NCATS/NIH

I would like to thank Drs. Peter Hedera, Michael Cooper and John Fang for assisting in the trial design.

\section{References}

1. Liang GS, Chou KL, Baltuch GH, Jaggi JL, Loveland-Jones C, Leng L, et al. Long-term outcomes of bilateral subthalamic nucleus stimulation in patients with advanced Parkinson's disease. Stereotact Funct Neurosurg. 2006; 84(5-6):221-7. [PubMed: 17063043]

2. Krack P, Batir A, Van Blercom N, Chabardes S, Fraix V, Ardouin C, et al. Five-year follow-up of bilateral stimulation of the subthalamic nucleus in advanced Parkinson's disease. N Engl J Med. 2003; 349(20):1925-34. [PubMed: 14614167]

3. Rodriguez-Oroz MC, Obeso JA, Lang AE, Houeto JL, Pollak P, Rehncrona S, et al. Bilateral deep brain stimulation in Parkinson's disease: a multicentre study with 4 years follow-up. Brain. 2005; 128(Pt 10):2240-9. [PubMed: 15975946]

4. Schupbach WM, Chastan N, Welter ML, Houeto JL, Mesnage V, Bonnet AM, et al. Stimulation of the subthalamic nucleus in Parkinson's disease: a 5 year follow up. J Neurol Neurosurg Psychiatry. 2005; 76(12):1640-4. [PubMed: 16291886]

5. Ostergaard K, Aa Sunde N. Evolution of Parkinson's disease during 4 years of bilateral deep brain stimulation of the subthalamic nucleus. Mov Disord. 2006; 21(5):624-31. [PubMed: 16283616]

6. Derost PP, Ouchchane L, Morand D, Ulla M, Llorca PM, Barget M, et al. Is DBS-STN appropriate to treat severe Parkinson disease in an elderly population? Neurology. 2007; 68(17):1345-55. [PubMed: 17452578]

7. Piboolnurak P, Lang AE, Lozano AM, Miyasaki JM, Saint-Cyr JA, Poon YY, et al. Levodopa response in long-term bilateral subthalamic stimulation for Parkinson's disease. Mov Disord. 2007; 22(7):990-7. [PubMed: 17443692]

8. Krystkowiak P, Blatt JL, Bourriez JL, Duhamel A, Perina M, Blond S, et al. Effects of subthalamic nucleus stimulation and levodopa treatment on gait abnormalities in Parkinson disease. Arch Neurol. 2003; 60(1):80-4. [PubMed: 12533092]

9. Markham CH, Diamond SG. Long-term follow-up of early dopa treatment in Parkinson's disease. Ann Neurol. 1986; 19(4):365-72. [PubMed: 3707088]

10. Xie T, Kang UJ, Warnke P. Effect of stimulation frequency on immediate freezing of gait in newly activated STN DBS in Parkinson's disease. J Neurol Neurosurg Psychiatry. 83(10):1015-7. Epub 2012/06/15. [PubMed: 22696586]

11. Moreau C, Defebvre L, Destee A, Bleuse S, Clement F, Blatt JL, et al. STN-DBS frequency effects on freezing of gait in advanced Parkinson disease. Neurology. 2008; 71(2):80-4. [PubMed: 18420482] 
12. Ricchi V, Zibetti M, Angrisano S, Merola A, Arduino N, Artusi CA, et al. Transient effects of 80 Hz stimulation on gait in STN DBS treated PD patients: a 15 months follow-up study. Brain stimulation.

13. Mazzone P, Lozano A, Stanzione P, Galati S, Scarnati E, Peppe A, et al. Implantation of human pedunculopontine nucleus: a safe and clinically relevant target in Parkinson's disease. Neuroreport. 2005; 16(17):1877-81. [PubMed: 16272871]

14. McIntyre CC, Mori S, Sherman DL, Thakor NV, Vitek JL. Electric field and stimulating influence generated by deep brain stimulation of the subthalamic nucleus. Clin Neurophysiol. 2004; 115(3): 589-95. [PubMed: 15036055]

15. Chien SL, Lin SZ, Liang CC, Soong YS, Lin SH, Hsin YL, et al. The efficacy of quantitative gait analysis by the GAITRite system in evaluation of parkinsonian bradykinesia. Parkinsonism Relat Disord. 2006; 12(7):438-42. [PubMed: 16798053] 
Table 1

Baseline Clinical data

\begin{tabular}{|c|c|c|}
\hline & Mean & Range \\
\hline Age & 62 & $52-72$ \\
\hline Duration of Disease, years & 12.5 & $5-22$ \\
\hline Time since DBS & 3 & 4 months-10 yrs \\
\hline Pre-op UPDRS III “on" & 14.8 & $2-31$ \\
\hline Pre-op UPDRS III “off” & 37.7 & $17-59$ \\
\hline Study baseline UPDRS & 22.8 & $16-31$ \\
\hline UPDRS Q\# 29 gait & 1.84 & $0-4$ \\
\hline UPDRS Q\#30, postural stability & 1.1 & $0-2$ \\
\hline Dopamine equivalents, study baseline & 842.5 & $0-1600$ \\
\hline DBS average voltage, study baseline & 2.6 & $0.9-3.8$ \\
\hline
\end{tabular}


Table 2

Outcome measures median (range)

\begin{tabular}{|c|c|c|}
\hline & $60 \mathrm{~Hz}$ & $130 \mathrm{~Hz}$ \\
\hline Stride length, $\mathrm{cm}$ & $1.19(-18.35-37.47)$ & $2.86(-11.33-31.93)$ \\
\hline Double limb support time, $\%$ gait cycle & $-0.22(-37.65-28.78)$ & $10.18(-7.80-18.25)$ \\
\hline Velocity, $\mathrm{cm} / \mathrm{sec}$ & $-0.15(-25.65-42.05)$ & $1.55(-18.3-30.1)$ \\
\hline Number of steps & $0(-65.5-25)$ & $0(-56.5-2)$ \\
\hline Ambulation time, sec & $0.21(-48.93-1.3)$ & $0.5(-49.8-1.89)$ \\
\hline Step length, cm & $0.85(-9.08-25)$ & $1.28(-5.91-16.1)$ \\
\hline Cycle time, sec & $-0.003(-0.88-2.39)$ & $0.02(-7.8-0.21)$ \\
\hline Heel-Heel base of support, cm & $-0.16(-4.46-5.82)$ & $-0.26(-1.74-17.46)$ \\
\hline Single limb support time, $\%$ gait cycle & $0.85(-1.63-5.8)$ & $0.35(-1.15-10.85)$ \\
\hline Swing time, $\%$ gait cycle & $0.85(-1.63-5.37)$ & $0.28(-2.38-4.45)$ \\
\hline Step Time, sec & $0.01(-0.78-0.21)$ & $0.01(-0.83-0.21)$ \\
\hline Stance time, $\%$ gait cycle & $0.85(-11.03-1.10)$ & $0.32(-6.72-1.10)$ \\
\hline Step ratio & $0.01(-64.89-0.24)$ & $0.01(-64.9-0.17)$ \\
\hline Toe in/out, degree & $-0.5(-4.25-2.75)$ & $0(-4.5-2)$ \\
\hline Cadence steps/min & $-2.15(-55.9-31.45)$ & $-2.90(-19.60-23.15)$ \\
\hline Step time differential, sec & $0.01(-0.096-0.06)$ & $0.01(-1.32-0.4)$ \\
\hline Step length differential, sec & $0.23(-13.85-7.10)$ & $-0.26(-10.22-4.20)$ \\
\hline Cycle time differential, sec & $0(0.4-0.03)$ & $-0.01(0.3-0.01)$ \\
\hline UPDRS III & $0(-5.5-4.5)$ & $-1.5(-7.5-1.5)$ \\
\hline UPDRS Q \#29 Gait (mean) & $0.43(-1.44-0.41)$ & $0.56(-0.55-0.34)$ \\
\hline UPDRS Q\#30 Postural Stability & $0.17(-0.48-0.13)$ & $0(0.13-0.32)$ (mean) \\
\hline
\end{tabular}


Table 3

\begin{tabular}{|c|c|c|c|c|}
\hline Subject & Electrode configuration L/R & Voltage L/R & Pulse Width L/R & Frequency L/R \\
\hline 1 & $\mathrm{C}+2-/ \mathrm{C}+15-$ & $3.2 / 3.2$ & $60 / 60$ & $130 / 130$ \\
\hline 2 & $\mathrm{C}+1-/ \mathrm{C}+2-$ & $0.9 / 1.5$ & $60 / 60$ & $130 / 130$ \\
\hline 3 & $0+3-/ 3+0-$ & $1.6 / 1.8$ & $60 / 60$ & $130 / 130$ \\
\hline 4 & $\mathrm{C}+1-/ \mathrm{C}+3-$ & $3.8 / 2.3$ & $90 / 90$ & $130 / 130$ \\
\hline 5 & $\mathrm{C}+1-/ \mathrm{C}+3-$ & $3.2 / 3.2$ & $60 / 60$ & $130 / 130$ \\
\hline 6 & $\mathrm{C}+1-/ \mathrm{C}+3-$ & $2.4 / 2.4$ & $60 / 60$ & $185 / 185$ \\
\hline 7 & $\mathrm{C}+2-/ \mathrm{C}+3-$ & $2.6 / 2.4$ & $90 / 90$ & $130 / 130$ \\
\hline 8 & $\mathrm{C}+1-/ \mathrm{C}+2-$ & $1.3 / 60$ & $60 / 60$ & $130 / 130$ \\
\hline 9 & $\mathrm{C}+2-/ \mathrm{C}+0-$ & $3.2 / 2.8$ & $90 / 60$ & $130 / 130$ \\
\hline 10 & $\mathrm{C}+1-/ \mathrm{C}+2-$ & $2.5 / 2.5$ & $60 / 60$ & $185 / 185$ \\
\hline 11 & $\mathrm{C}+1-/ \mathrm{C}+2-$ & $2.2 / 0.9$ & $90 / 90$ & $130 / 130$ \\
\hline 12 & $\mathrm{C}+1-2-/ \mathrm{C}+2-$ & $3.2 / 2.7$ & $90 / 90$ & $130 / 130$ \\
\hline 13 & $\mathrm{C}+3-/ \mathrm{C}+0-$ & $2.2 / 1.7$ & $60 / 60$ & $130 / 130$ \\
\hline 14 & $\mathrm{C}+3-/ \mathrm{C}+3-$ & $3.7 / 3.7$ & $60 / 60$ & $130 / 130$ \\
\hline 15 & $\mathrm{C}+2-/ \mathrm{C}+3-$ & $3.5 / 3.5$ & $60 / 60$ & $130 / 130$ \\
\hline 16 & $\mathrm{C}+3-/ \mathrm{C}+1-$ & $2.2 / 2.2$ & $90 / 90$ & $130 / 130$ \\
\hline 17 & $\mathrm{C}+3-/ \mathrm{C}+3-$ & $2.8 / 3.8$ & $60 / 60$ & $130 / 130$ \\
\hline 18 & $\mathrm{C}+2-/ \mathrm{C}+2-$ & $2.0 / 2.0$ & $60 / 60$ & $130 / 130$ \\
\hline 19 & $\mathrm{C}+2-/ 3+1-$ & $1.8 / 3.0$ & $90 / 90$ & $130 / 130$ \\
\hline 20 & $3+1-/ 3+1-$ & $3.2 / 3.1$ & $90 / 90$ & $185 / 185$ \\
\hline
\end{tabular}

